\title{
Urine Monocyte Chemoattractant Protein-1 and Lupus Nephritis Disease Activity: Preliminary Report of a Prospective Longitudinal Study
}

\author{
Sabah Alharazy, ${ }^{1}$ Norella C. T. Kong, ${ }^{1}$ Marlyn Mohd, ${ }^{2}$ Shamsul A. Shah, ${ }^{3}$ \\ Arbaiyah Ba'in, ${ }^{1}$ and Abdul Halim Abdul Gafor ${ }^{1}$ \\ ${ }^{1}$ Nephrology Unit, Department of Medicine, Universiti Kebangsaan Malaysia Medical Centre, 56000 Kuala Lumpur, Malaysia \\ ${ }^{2}$ Department of Medical Microbiology \& Immunology, Universiti Kebangsaan Malaysia Medical Centre, \\ 56000 Kuala Lumpur, Malaysia \\ ${ }^{3}$ Department of Community Medicine, Universiti Kebangsaan Malaysia Medical Centre, 56000 Kuala Lumpur, Malaysia
}

Correspondence should be addressed to Sabah Alharazy; sabah_alharazy@yahoo.co.uk

Received 23 January 2015; Revised 12 April 2015; Accepted 15 April 2015

Academic Editor: Ricard Cervera

Copyright (C) 2015 Sabah Alharazy et al. This is an open access article distributed under the Creative Commons Attribution License, which permits unrestricted use, distribution, and reproduction in any medium, provided the original work is properly cited.

\begin{abstract}
Objective. This longitudinal study aimed to determine the urine monocyte chemoattractant protein-1 (uMCP-1) levels in patients with biopsy-proven lupus nephritis ( $\mathrm{LN}$ ) at various stages of renal disease activity and to compare them to current standard markers. Methods. Patients with LN-active or inactive-had their uMCP-1 levels and standard disease activity markers measured at baseline and 2 and 4 months. Urinary parameters, renal function test, serological markers, and renal SLE disease activity index-2K (renal SLEDAI-2K) were analyzed to determine their associations with uMCP-1. Results. A hundred patients completed the study. At each visit, uMCP-1 levels (pg/mg creatinine) were significantly higher in the active group especially with relapses and were significantly associated with proteinuria and renal SLEDAI-2K. Receiver operating characteristic (ROC) curves showed that uMCP-1 was a potential biomarker for LN. Whereas multiple logistic regression analysis showed that only proteinuria and serum albumin and not uMCP-1 were independent predictors of LN activity. Conclusion. uMCP-1 was increased in active LN. Although uMCP-1 was not an independent predictor for LN activity, it could serve as an adjunctive marker when the clinical diagnosis of LN especially early relapse remains uncertain. Larger and longer studies are indicated.
\end{abstract}

\section{Introduction}

Lupus nephritis (LN) contributes to significant morbidity and mortality in patients with systemic lupus erythematosus (SLE) $[1,2]$. Renal biopsy is the gold standard for diagnosis of LN. However, repeated biopsies are not always practical in real life practice especially in patients with frequent relapses or in those with associated severe haematologic or cerebral manifestations. Moreover, renal biopsy is a relatively invasive procedure and is associated with a significant albeit small risk, particularly in those patients who may have undiagnosed coagulopathy, for example, presence of antiphospholipid antibodies/antiphospholipid syndrome, or are on anticoagulants [3].
Active LN especially early flares/relapses often respond to appropriate treatment with immunosuppressive agents. However, these drugs are themselves associated with significant morbidity and even mortality whilst uncontrolled LN activity leads to chronic or end stage kidney disease (ESRD) and even death. Current standard laboratory markers such as proteinuria cannot always distinguish between active and inactive renal disease especially in patients with a recent history of LN [4]. These tests also lack sensitivity and specificity for the monitoring of LN activity especially early flares. Hence, it is essential to identify noninvasive new biomarkers that are able to predict renal flares/relapses as well as reflect the severity of LN activity. These biomarkers could be followed serially and may enable timely institution of 
appropriate treatment before the development of significant inflammatory injury in the kidney.

Monocyte chemoattractant protein-1 (MCP1) is a chemokine that attracts monocytes/macrophages to sites of inflammation [5]. MCP-1 is produced by mesangial, podocyte, and monocyte cells in response to various proinflammatory stimuli such as tumor necrosis factor alpha (TNF- $\alpha$ ). These inflammatory cells and substances subsequently mediate tissue injury and contribute to the development of renal dysfunction. Moreover, MCP-1 binding has been shown to reduce levels of nephrin, an important protector of kidney cell function [6] whereas antagonists to MCP-1 prevent renal disease progression in murine models. Marks et al. [7] showed that the presence of MCP-1 within the glomerulus correlated with a poor renal prognosis and could identify more severe histological classes of $\mathrm{LN}$ in paediatric patients.

Several studies have shown that the urine levels of MCP-1 were significantly greater in patients undergoing a renal flare than in patients with stable renal disease or healthy controls [8-10].

We have previously reported that, in a cross-sectional study of 100 adult SLE patients with LN, uMCP-1 levels did reflect LN activity [11]. In this paper, we present the preliminary results of our prospective follow-up study which evaluated uMCP-1 as a potential marker for LN response to treatment and/or early relapse in this same LN patient cohort.

\section{Methods}

The same $100 \mathrm{LN}$ patients whose baseline data had been previously reported by us $[11,12]$ were followed in a prospective longitudinal fashion at 2 and 4 months. All patients fulfilled the ACR classification criteria for SLE [13] and eligibility included all those with biopsy-proven LN regardless of activity status at recruitment. We excluded LN patients with ESRD or who required chronic dialysis or had undergone renal transplantation and those with clinical LN in whom a renal biopsy could not be performed as well as pregnant patients. The patients were divided into two groups based on the presence or absence of LN activity as detailed below. The active LN group included those with active renal disease or nonremission (NR) or who had a relapse/flare. The inactive LN group included those in complete or partial remission (CR/PR). The calculated sample size was 100 patients [11]. Informed consent was obtained from all recruited subjects. The study protocol was approved by the Medical Research and Ethics Committee of the Universiti Kebangsaan Malaysia Medical Centre (UKMMC).

\subsection{Definition of LN Activity}

(A) Active $\mathrm{LN}$ was defined by the presence of one or more of the following criteria.

(I) Proteinuria with or without any of the following features [14]:

(a) presence of haematuria and/or red cell casts,

(b) increase in serum creatinine and/or decline in eGFR.
Proteinuria was measured as a spot morning urine protein creatinine index (uPCI) and was positive if the value was $>100 \mathrm{mg} / \mathrm{mmol}$ creatinine $(\mathrm{NR} \leq 20)$.

(II) Renal SLEDAI score $\geq 4$ (out of 16) [15].

(B) Relapse/flare of LN was defined in two ways.

(I) At recruitment, relapse was defined as recurrence of renal disease activity after a period of remission $\geq 3$ months [14].

(II) During this study period with only 4 months of observation (due to time constraints), relapse was defined as an increase in proteinuria and/or haematuria and/or serum creatinine level after 4 weeks of $\mathrm{CR} / \mathrm{PR}$ or decrease in serum albumin level after 4 weeks of CR/PR [14].

(C) Remission was also defined in two ways.

(I) At recruitment, remission was defined as absence or reduction of renal disease activity and no change in immunosuppressive therapy for at least 3 months [14].

(II) In this study period with only 4 months of observation, remission was defined as absence or reduction of renal disease activity and no change in immunosuppressive therapy for at least 4 weeks [14].

(D) Inactive LN was defined by the presence of one or more of the following criteria.

(I) Proteinuria (uPCI) $\leq 50 \mathrm{mg} / \mathrm{mmol}$ with/without any of the following features [14]:

(a) serum albumin $\geq 35 \mathrm{~g} / \mathrm{L}$,

(b) inactive urine sediments [no red blood cells $(\mathrm{RBC}<5$ red cells/HPF), no red cell casts and no leucocyturia $(<5$ white cells/HPF)],

(c) stable serum creatinine (unless due to another aetiology, e.g., renin-angiotensin system (RAS) blockade).

(II) Renal SLEDAI score 0 or $<4 / 16$.

2.2. The Disease Course of $L N$. The disease course of LN was categorized at each visit using the definitions modified from Yamaji et al. [16] and Ruiz-Irastorza et al. [17] (Table 1).

(1) Complete remission (CR).

(2) Partial remission (PR).

(3) Nonremission (NR) or unchanged.

(4) Relapse/flare.

2.3. SLE Disease Activity Index and Laboratory Assessment. SLE Disease Activity Index (SLEDAI-2K) was used to assess 
TABLE 1: Criteria for the definition of the course of lupus nephritis.

\begin{tabular}{|c|c|c|c|c|}
\hline \multirow{2}{*}{ Outcome } & \multicolumn{4}{|c|}{ Criteria } \\
\hline & Proteinuria (uPCI) & Haematuria & Serum creatinine & Serum albumin \\
\hline Complete remission (CR) & $\leq 50 \mathrm{mg} / \mathrm{mmol}$ creatinine & $\begin{array}{c}<10 \mathrm{RBC} \times 10^{6} / \mathrm{L}+\text { no } \mathrm{RBC} \\
\text { casts }\end{array}$ & $\begin{array}{l}\text { Baseline or } \leq 25 \% \\
\text { increase }\end{array}$ & $\geq 35 \mathrm{~g} / \mathrm{L}$ \\
\hline Partial remission (PR) & $\begin{array}{c}50 \% \text { reduction in baseline } \\
\text { or }>50 \leq 300 \mathrm{mg} / \mathrm{mmol} \\
\text { creatinine }\end{array}$ & $\begin{array}{c}>10<50 \mathrm{RBC} \times 10^{6} / \mathrm{L}+\text { no } \\
\mathrm{RBC} \text { casts }\end{array}$ & $\begin{array}{l}\text { Baseline or } \leq 25 \% \\
\text { increase }\end{array}$ & $\geq 35 \mathrm{~g} / \mathrm{L}$ \\
\hline Nonremission (NR) & $\begin{array}{c}\text { No change or } \\
>300 \mathrm{mg} / \mathrm{mmol} \text { creatinine }\end{array}$ & $\begin{array}{c}\geq 50<150 \mathrm{RBC} \times 10^{6} / \mathrm{L} \pm \\
\mathrm{RBC} \text { casts }\end{array}$ & $\geq 25 \%$ increase & $<35 \mathrm{~g} / \mathrm{L}$ \\
\hline Relapse/flare & $\begin{array}{c}\text { Increase after } 4 \text { weeks of } \\
\text { CR/PR }\end{array}$ & $\begin{array}{c}\text { Increase after } 4 \text { weeks of } \\
\text { CR/PR }\end{array}$ & $\begin{array}{c}\text { Increase after } 4 \text { weeks of } \\
\text { CR/PR }\end{array}$ & $\begin{array}{c}\text { Decrease after } 4 \text { weeks of } \\
\text { CR/PR }\end{array}$ \\
\hline
\end{tabular}

Adapted with modification from Yamaji et al. [16] and Ruiz-Irastorza et al. [17].

lupus disease activity [15]. This index consists of three components: global (score range 0-150), renal (score range $0-16$ ), and extrarenal (score range $0-63$ ). The renal score corresponds to the presence of any one of the following on urinalysis: proteinuria, haematuria, leukocyturia, or urinary red cell casts after exclusion of stones or concurrent urinary tract infection or other causes of proteinuria [18].

Laboratory assessment included the following: full blood count, renal function test, estimated glomerular filtration rate (eGFR) using the Modification of Diet in Renal Disease (MDRD) formula, urinalysis, urine microscopy, urine protein creatinine index (uPCI), and serological tests (serum complement 3 and 4 levels (C3, C4) and anti-dsDNA antibody titres (anti-dsDNA Ab)).

2.4. Urine Sample Collection. A fresh urine sample (midstream) from each patient was collected in a sterile container. The urine was then transferred to $3 \times 10 \mathrm{~mL}$ tubes. These were transported directly to the laboratory where they were centrifuged for 15 minutes at $1500 \mathrm{~g}$ to remove sediments then frozen in aliquots at $-80^{\circ} \mathrm{C}$ for later uMCP-1 testing.

2.5. Method of Measuring Urinary MCP-1. CCL2/MCP-1 Quantikine ELISA KIT (R\&D Systems USA) for urinary MCP-1 measurement was used. The Quantikine Human MCP-1 Immunoassay is a 3.5-4.5-hour solid phase ELISA designed to measure MCP-1 in cell culture supernates, serum, plasma, and urine. It contains $E$. coli expressed recombinant human MCP-1 and antibodies against the recombinant factor. It accurately quantifies recombinant human MCP-1. Results obtained show linear curves that are parallel to the standard curves obtained using the Quantikine kit standards.

\section{Statistical Analysis}

Categorical variables are presented as counts (percent). Continuous variables are presented as mean ( \pm standard deviation (SD)) if normally distributed or median (interquartile range (IQR)) if nonnormally distributed. Pearson's chi-square test $\left(\chi^{2}\right)$ was used to compare categorical variables and a two-sided independent-sample $t$-test was used to compare normally distributed variables. Nonparametric tests (MannWhitney $U$ and Kruskal-Wallis tests) were used for nonnormally distributed variables. Spearman's correlation coefficient was used to assess the association between uMCP-1 levels with standard laboratory parameters.

Receiver operating characteristic (ROC) curves were constructed to determine the performance characteristics of uMCP-1 levels for detection and prediction of LN activity. The best cutoff value for uMCP-1 was calculated based on maximization of the Youden index (sensitivity + specificity 1) [19]. Sensitivity, specificity, positive predictive value (PPV), and negative predictive value (NPV) of uMCP-1 as predictor of LN activity were also calculated.

Binary logistic regression analysis was performed to explore for independent predictors of LN activity. uMCP-1 and all standard markers of LN activity of the preceding visit with a $p<0.05$ were included in the regression model. Data was analyzed using SPSS software version 18.0. Probability $(p)$ values of $<0.05$ were considered significant.

\section{Results}

4.1. Characteristics of the Study Population. A total of 100 SLE patients with biopsy proven LN were recruited and all completed the 4-month observation period. The sociodemographic, clinical, and laboratory data between active and inactive LN groups are as shown in Table 2.

4.2. Course of LN in the Overall Study Population. At baseline, there were 47 patients with active LN (42 NR, 5 relapses) and 53 with inactive LN. The number with active LN decreased to 29 ( $27 \mathrm{NR}, 2$ relapses) at 2 months and to 22 (16 NR, 6 relapses) at 4 months, respectively, whereas the number of patients with inactive LN increased progressively from 53 at baseline to 71 (61 CR, $10 \mathrm{PR}$ ) at 2 months to 78 (59 CR, $19 \mathrm{PR})$ at 4 months, respectively. In summary, with time on treatment, the majority of patients with active LN achieved $\mathrm{CR} / \mathrm{PR}$ although a few relapses occurred at each follow-up.

At each time point, there were significant differences between the active and inactive $\mathrm{LN}$ groups with regard to serum albumin $(p<0.01)$, proteinuria (uPCI, $p<0.001$ ), SLEDAI-2K (global) $(p<0.001)$, and SLEDAI-2K (renal) $(p<0.001)$. At end study, serum creatinine had increased 
TABLE 2: Baseline demographic and characteristics in the active and inactive LN patient groups.

\begin{tabular}{|c|c|c|c|c|}
\hline Parameters & $\begin{array}{c}\text { All subjects } \\
n=100\end{array}$ & $\begin{array}{c}\text { Active LN } \\
n=47\end{array}$ & $\begin{array}{c}\text { Inactive LN } \\
n=53\end{array}$ & $p$ value \\
\hline Age, mean \pm SD years & $36.90 \pm 10.62$ & $36.40 \pm 9.97$ & $37.33 \pm 11.24$ & 0.74 \\
\hline Female: number (\%) & $92(92 \%)$ & $43(91.5 \%)$ & $49(92.5 \%)$ & 0.57 \\
\hline Male: number (\%) & $8(8 \%)$ & $4(8.5 \%)$ & $4(7.5 \%)$ & \\
\hline \multicolumn{5}{|l|}{ Race: number (\%) } \\
\hline Malay & $41(41 \%)$ & $24(51.1 \%)$ & $17(32.1 \%)$ & \\
\hline Chinese & $55(55 \%)$ & $21(44.7 \%)$ & $34(64.2 \%)$ & 0.14 \\
\hline Indian & $4(4 \%)$ & $2(4.3 \%)$ & $2(3.8 \%)$ & \\
\hline LN duration in years & $7(1-24)$ & $7(1-24)$ & $7(1-17)$ & 0.56 \\
\hline Mixed connective tissue disease (MCTD) & $7(7 \%)$ & $3(6.4 \%)$ & $4(7.5 \%)$ & 0.82 \\
\hline Musculoskeletal system (MSK) & $41(41 \%)$ & $20(42.6 \%)$ & $21(39.6 \%)$ & 0.46 \\
\hline Duration of MSK in years & $6(1-27)$ & $6.5(1-27)$ & $6(1-27)$ & 0.60 \\
\hline Autoimmune Haemolytic Anaemia (AIHA) & $26(26 \%)$ & $14(29.8 \%)$ & $12(22.6 \%)$ & 0.27 \\
\hline Duration of AIHA in years & $4.88 \pm 3.21$ & $5.58 \pm 3.44$ & $4.28 \pm 2.99$ & 0.34 \\
\hline Idiopathic thrombocytopenic purpura (ITP) & $9(9 \%)$ & $5(10.6 \%)$ & $4(7.5 \%)$ & 0.24 \\
\hline Duration of ITP in years & $7.5 \pm 4.62$ & $9.5 \pm 5.8$ & $5.5 \pm 2.38$ & 0.20 \\
\hline Thrombotic thrombocytopenic purpura (TTP) & $1(1 \%)$ & $0(0 \%)$ & $1(1 \%)$ & 0.53 \\
\hline Systolic blood pressure (mmHg) & $128 \pm 17.68$ & $128 \pm 13.16$ & $120 \pm 13.91$ & 0.001 \\
\hline Diastolic blood pressure (mmHg) & $75.2 \pm 4.08$ & $77.80 \pm 10.31$ & $73.68 \pm 10.44$ & 0.04 \\
\hline \multicolumn{5}{|l|}{ Classes of lupus nephritis (\%) } \\
\hline WHO class I & $1(1 \%)$ & $1(2.1 \%)$ & $0(0 \%)$ & \multirow{6}{*}{0.71} \\
\hline WHO class II $\pm \mathrm{V}$ & $6(6 \%)$ & $3(6.4 \%)$ & $3(5.7 \%)$ & \\
\hline WHO class III $\pm \mathrm{V}$ & $34(34 \%)$ & $15(31.9 \%)$ & $19(35.8 \%)$ & \\
\hline WHO class IV $\pm \mathrm{V}$ & $52(52 \%)$ & $26(55.3 \%)$ & $26(49.1 \%)$ & \\
\hline WHO class $\mathrm{V}$ & $5(5 \%)$ & $1(2.1 \%)$ & $4(7.5 \%)$ & \\
\hline WHO class VI & $2(2 \%)$ & $1(2.1 \%)$ & $1(1.9 \%)$ & \\
\hline Activity index, median (IQR) & $8(0-19)$ & $9(0-16)$ & $8(0-19)$ & 0.93 \\
\hline Chronicity index, median (IQR) & $3(0-15)$ & $3.58(0-9)$ & $3(1-15)$ & 0.55 \\
\hline \multicolumn{5}{|l|}{ CKD stage $(\%)$} \\
\hline Stage $1($ eGFR > 90) & $61(61 \%)$ & $25(53.2 \%)$ & $36(67.9 \%)$ & \multirow{4}{*}{0.06} \\
\hline Stage 2 (eGFR 60-89) & $22(22 \%)$ & $10(21.3 \%)$ & $12(22.6 \%)$ & \\
\hline Stage 3 (eGFR 30-59) & $14(14 \%)$ & $9(19.1 \%)$ & $5(9.4 \%)$ & \\
\hline Stage 4 (eGFR 15-29) & $3(3 \%)$ & $3(6.4 \%)$ & $0(0 \%)$ & \\
\hline \multicolumn{5}{|l|}{ Medications, no (\%) } \\
\hline Corticosteroids & $95(95 \%)$ & $43(91.5 \%)$ & $52(98.1 \%)$ & 0.12 \\
\hline Cumulative dose for previous six months (g) & $1.80(0.75-4.50)$ & $1.80(0.90-4.50)$ & $1.76(0.75-1.95)$ & 0.001 \\
\hline Cumulative dose from previous relapse (g) & $\begin{array}{c}5.040 \\
(0.90-24.43)\end{array}$ & $\begin{array}{c}4.415 \\
(0.90-24.43)\end{array}$ & $\begin{array}{c}6.685 \\
(1.59-13.32)\end{array}$ & 0.009 \\
\hline Time from last relapse (months) & $22(1-120)$ & $11(1-120)$ & $28(3.5-72)$ & 0.001 \\
\hline Cyclophosphamide & $8(8 \%)$ & $8(17 \%)$ & $0(0 \%)$ & 0.002 \\
\hline Cyclosporine A/Tacrolimus & $30(30 \%)$ & $19(40.4 \%)$ & $11(20.8 \%)$ & 0.03 \\
\hline Mycophenolic acid & $22(22 \%)$ & $12(25.5 \%)$ & $10(18.9 \%)$ & 0.42 \\
\hline Azathioprine & $36(36 \%)$ & $12(25.5 \%)$ & $24(45.3 \%)$ & 0.04 \\
\hline Hydroxychloroquine & $42(42 \%)$ & $20(42.6 \%)$ & $22(41.5 \%)$ & 0.91 \\
\hline Renin angiotensin system blockers (ACEI/ARB/spironolactone) & $68(68 \%)$ & $29(61.7 \%)$ & $39(73.6 \%)$ & 0.11 \\
\hline
\end{tabular}

SD: standard deviation; IQR: interquartile range; LN: lupus nephritis; WHO: World Health Organization; CKD: chronic kidney disease; ACEI: angiotensin converting enzyme inhibitors; ARBs: angiotensin receptor blockers; NS: not significant. 
and eGFR declined significantly only in the active LN group. There were no differences between both groups in terms of anti-dsDNA Ab and serum complements (C3 and C4).

The detailed comparisons between active and inactive LN groups at each time point are summarized in Table 3. At all time points, uMCP-1 levels were significantly higher in the active group compared to those in the inactive LN group (Table 3).

4.2.1. uMCP-1 Levels on Longitudinal Follow-Up. On longitudinal follow-up, uMCP-1 levels also differed significantly between those patients who attained CR/PR compared with those with NR or who relapsed.

At baseline, patients with CR/PR had median uMCP1 levels of $3,682 \mathrm{pg} / \mathrm{mg}$ creatinine (IQR 6,426.05, range $0-23,866$ ) compared with $7,499.33 \mathrm{pg} / \mathrm{mg}$ creatinine (IQR 11,303.36, range 548.30-40,170) in those with NR and $14,962.66 \mathrm{pg} / \mathrm{mg}$ creatinine (IQR 10,622 , range $560-16,897$ ) in those who relapsed $(p=0.002)$.

At 2 months, patients who achieved CR/PR had median uMCP-1 levels of 2,496 pg/mg creatinine (IQR 3,536.17, range 0-13,412) compared with $4,900 \mathrm{pg} / \mathrm{mg}$ creatinine (IQR 4,795 range $1,953.79-18,458)$ in those with NR and $9,654.66 \mathrm{pg} / \mathrm{mg}$ creatinine (range 8,711.33-10,538) in those who relapsed ( $p<$ $0.001)$.

At 4 months, patients who achieved CR/PR had median uMCP-1 levels of 2,220.84 pg/mg creatinine (IQR 2,028.17, range $0-11,470$ ) compared with $7,288.50 \mathrm{pg} / \mathrm{mg}$ creatinine (IQR 5,507.61 range 1,208.69-13,716) in those with NR and $10,210.64 \mathrm{pg} / \mathrm{mg}$ creatinine (IQR 8,092 , range $0-51,221$ ) in those who relapsed $(p<0.001)$.

At each visit, uMCP-1 levels were highest in those patients with relapsed LN followed by the NR group and the lowest levels occurred in the remission group (CR/PR).

4.2.2. Association between $u M C P-1$ with Parameters of $L N$ Activity on Follow-Up. The associations of uMCP-1 with parameters of LN activity are summarized in Table 4 .

4.3. Course of LN in the Group Active at Baseline. At baseline, the active LN group comprised 47 patients, $42 \mathrm{NR}$ and five relapsers. At 2 months of follow-up, 18/47 (38\%) achieved CR/PR, 27/47 (57.4\%) had NR, and 2/47 (4\%) relapsed. At 4 months, 28/47 (60\%) achieved CR/PR, 16/47 (34\%) had NR, and 3/47 (6\%) relapsed (Table 5).

Two patients were subjected to repeat renal biopsy. In both, the histopathological findings had deteriorated from class II + V (Case 1) and class IV (Case 2) six months earlier to class III $+\mathrm{V}$ (both).

4.3.1. UMCP-1 Levels and LN Activity on Follow-Up. The uMCP-1 levels decreased progressively from baseline to 2 months to end of study in response to treatment especially in those patients who achieved remission (Table 5). uMCP-1 levels were significantly lower in those who attained remission than in those with active $\mathrm{LN}$ ( $p<0.001$ in both).

4.4. Lupus Nephritis Relapses. On follow-up, 13 patients in the overall study population relapsed, five at baseline, two

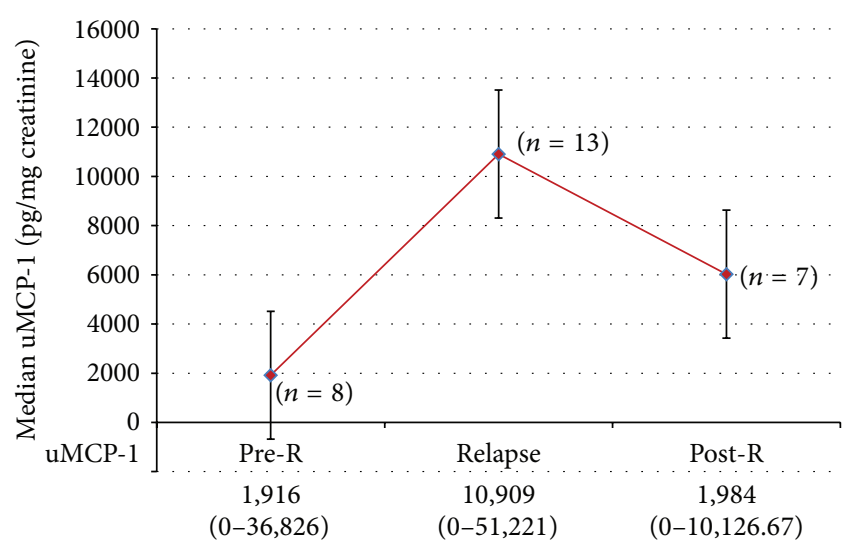

FIgURE 1: Median uMCP-1 levels in LN relapse compared to pre- and postrelapse levels.

at 2 months, and six at 4 months, and were appropriately treated. Their median uMCP-1 levels were highest at the time of relapse compared to pre-relapse levels and decreased in response to treatment (Figure 1). Renal biopsy was repeated in $1 / 5$ who relapsed at baseline and $1 / 2$ at 2 months but in none of the six relapsers at 4 months. Their histological findings had deteriorated from class IV to class $\mathrm{V}$ and mixed class IV $+\mathrm{V}$, respectively.

4.5. ROC Curve Analysis of uMCP-1 to Identify LN Activity. ROC curves were constructed to assess the potential diagnostic values of uMCP-1 compared with standard blood and urine markers at each visit to identify patients with active LN.

At each visit, the area under the curve (AUC) for uMCP-1 was higher than those for serum albumin, serum creatinine, eGFR, anti-dsDNA Ab titres, C3, and C4, for detection of LN activity (Table 6), whereas it was lower than those for proteinuria (uPCI) and SLEDAI-2K renal score. Thus, uMCP-1 was superior to most of the usual markers used for the monitoring of LN activity but was not as good as those for proteinuria (uPCI) and SLEDAI-2K renal score. This is illustrated by the ROC curves at end of study (Figure 2) which show that the AUC for uMCP-1 was very good at 0.87 (95\% CI: 0.78-0.96: $p<0.001$ ). At a maximum Youden index of 0.69 , the cutoff value was $3,594 \mathrm{pg} / \mathrm{mg}$ creatinine. This gave a sensitivity of 0.90 and a specificity of 0.79 , respectively.

4.6. Independent Predictors of LN Activity. Binary logistic regression was used to assess the independent predictors of LN activity. uMCP-1 and all relevant clinical variables with a $p$ value $\leq 0.05$ (Table 3 ) at 2 months were entered into the regression model to predict $\mathrm{LN}$ outcome at 4 months. These included serum albumin, serum creatinine, eGFR, proteinuria (uPCI), and SLEDAI-2K (renal) (Table 7). Only increasing proteinuria ( $\mathrm{uPCI})(\mathrm{OR}=4.93,95 \% \mathrm{CI}, 2.59-9.95$, $p=0.03)$ and a fall in the serum albumin ( $\mathrm{OR}=0.83,95 \%$ CI, 0.71-0.97, $p=0.02$ ) emerged as independent predictors of LN activity.

A ROC curve was also constructed for uMCP-1 levels of the previous visit (i.e., at 2 months) to predict LN outcome 
TABLE 3: Characteristics of patients with active and inactive $L N$ at each time point.

\begin{tabular}{|c|c|c|c|}
\hline Parameters & Baseline & 2 months & 4 months \\
\hline Active LN (A) & $\mathrm{A}, n=47$ & A, $n=29$ & $\mathrm{~A}, n=22$ \\
\hline Inactive LN (IA) & $\mathrm{IA}, n=53$ & IA, $n=71$ & IA, $n=78$ \\
\hline Serum albumin & $37.78 \pm 5.54$ & $39 \pm 5$ & $37.5 \pm 4.97$ \\
\hline$(35-50 \mathrm{~g} / \mathrm{L})$ & $41.88 \pm 3.59$ & $41.78 \pm 3.20$ & $41.02 \pm 5.82$ \\
\hline Intergroup $p$ value & $<0.001$ & $<0.001$ & 0.01 \\
\hline Serum creatinine & 69 (IQR 33-252) & 72 (IQR 30-244) & 89.5 (IQR 43-244) \\
\hline$(44-80 \mu \mathrm{mol} / \mathrm{L})$ & 63 (IQR 41-158) & 65 (IQR 37-168) & 63 (IQR 34-192) \\
\hline Intergroup $p$ value & 0.29 & 0.36 & 0.004 \\
\hline eGFR & $93.61 \pm 46.01$ & $91 \pm 49.16$ & $75.04 \pm 39.95$ \\
\hline$\left(>60 \mathrm{~mL} / \mathrm{min} / 1.73 \mathrm{~m}^{2}\right)$ & $99.75 \pm 31.54$ & $98 \pm 32.69$ & $98.35 \pm 35$ \\
\hline Intergroup $p$ value & 0.43 & 0.53 & 0.009 \\
\hline ESR & 38.5 (IQR 21-91) & 41 (IQR 22-92) & 32 (IQR 8-105) \\
\hline$(\mathrm{mm} / \mathrm{hr})$ & 33 (IQR 0-46) & 49 (IQR 10-103) & 36 (IQR 1-78) \\
\hline Intergroup $p$ value & 0.37 & 0.86 & 0.36 \\
\hline Anti-dsDNA Ab titers & 35.18 (IQR 1.73-195.97) & 30.23 (IQR 0.74-267.61) & 41.53 (IQR 2.07-291.62) \\
\hline$(<30 \mathrm{IU} / \mathrm{dL})$ & 24.24 (IQR 0.81-279.21) & 14.37 (IQR 1.05-280) & 18.90 (IQR 0.95-262.21) \\
\hline Intergroup $p$ value & 0.84 & 0.89 & 0.73 \\
\hline Serum C3 & $100.5 \pm 36.39$ & $102.25 \pm 40.53$ & $94.26 \pm 26.67$ \\
\hline$(79-152 \mathrm{mg} / \mathrm{dL})$ & $109.62 \pm 39.94$ & $106.37 \pm 41.54$ & $104.16 \pm 33.04$ \\
\hline Intergroup $p$ value & 0.24 & 0.32 & 0.21 \\
\hline Serum C4 & $21.46 \pm 12.82$ & $21.14 \pm 10.95$ & $22.81 \pm 10.19$ \\
\hline$(16-38 \mathrm{mg} / \mathrm{dL})$ & $22.94 \pm 11$ & $23.95 \pm 13.69$ & $23.14 \pm 9.48$ \\
\hline Intergroup $p$ value & 0.54 & 0.32 & 0.89 \\
\hline Proteinuria (uPCI) & 110 (IQR 10-510) & 130 (IQR 10-480) & 110 (IQR 10-510) \\
\hline (<20 mg/mmol creatinine) & 20 (IQR 10-50) & 20 (IQR 10-50) & 20 (IQR 10-30) \\
\hline Intergroup $p$ value & $<0.001$ & $<0.001$ & $<0.001$ \\
\hline \multirow[t]{2}{*}{ Urinary leucocytes $/ \mathrm{HPF} \times 10^{6} / \mathrm{L}$} & $0(0-20)$ & $0(0-20)$ & $0(0-20)$ \\
\hline & $0(0-5)$ & $0(0-15)$ & $0(0-10)$ \\
\hline Intergroup $p$ value & $<0.001$ & 0.30 & 0.007 \\
\hline Urinary & $0(0-10)$ & $0(0-20)$ & $0(0-50)$ \\
\hline $\mathrm{RBC} / \mathrm{HPF} \times 10^{6} / \mathrm{L}$ & $0(0-5)$ & $0(0-15)$ & $0(0-30)$ \\
\hline Intergroup $p$ value & $<0.001$ & 0.40 & 0.03 \\
\hline uMCP-1 & 9,317 (IQR 548-40,170) & 5,163 (IQR 1,953.79-18,458) & 7,288 (IQR 0-51,221) \\
\hline (pg/mg creatinine) & 3,682 (IQR 0-23.866) & 2,496 (IQR 0-13,412) & 2,220 (IQR 0-11,470) \\
\hline Intergroup $p$ value & $<0.001$ & $<0.001$ & $<0.001$ \\
\hline SLEDAI-2K & 8 (IQR 0-18) & 6 (IQR 0-18) & 8 (IQR 0-20) \\
\hline (global: 0-105) & 2 (IQR 0-10) & 2 (IQR 0-12) & 2 (IQR 0-17) \\
\hline Intergroup $p$ value & $<0.001$ & $<0.001$ & $<0.001$ \\
\hline SLEDAI-2K & 4 (IQR 0-16) & 4 (IQR 0-12) & 4 (IQR 0-16) \\
\hline (renal: 0-16) & 0 (IQR 0-3) & 0 (IQR 0-8) & 0 (IQR 0-12) \\
\hline Intergroup $p$ value & $<0.001$ & $<0.001$ & $<0.001$ \\
\hline SLEDAI-2K & 4 (IQR 0-12) & 2 (IQR 0-10) & 4 (IQR 0-12) \\
\hline (extrarenal: 0-89) & $2($ IQR $0-10)$ & 2 (IQR 0-9) & 2 (IQR 0-8) \\
\hline Intergroup $p$ value & 0.66 & 0.18 & 0.10 \\
\hline
\end{tabular}


TABLE 4: Association of UMCP-1 with parameters of LN activity on follow-up.

\begin{tabular}{|c|c|c|c|c|c|c|}
\hline \multirow{2}{*}{$\begin{array}{l}\text { Spearman's rho variable } \\
\text { (active : inactive LN) }\end{array}$} & \multicolumn{2}{|c|}{ Baseline (47:53) } & \multicolumn{2}{|c|}{2 months $(29: 71)$} & \multicolumn{2}{|c|}{4 months $(22: 78)$} \\
\hline & $r_{\mathrm{sp}}$ & $p$ value & $r_{\mathrm{sp}}$ & $p$ value & $r_{\mathrm{sp}}$ & $p$ value \\
\hline Serum albumin & -0.35 & 0.001 & -0.32 & 0.001 & -0.22 & 0.03 \\
\hline Serum creatinine & 0.09 & 0.38 & 0.14 & 0.15 & 0.24 & 0.01 \\
\hline eGFR & -0.10 & 0.30 & -0.15 & 0.12 & -0.24 & 0.01 \\
\hline Anti-dsDNA Ab titers (IU) & -0.04 & 0.64 & -0.19 & 0.06 & 0.01 & 0.89 \\
\hline $\mathrm{C} 3(\mathrm{mg} / \mathrm{dL})$ & -0.09 & 0.34 & -0.29 & 0.003 & -0.04 & 0.70 \\
\hline $\mathrm{C} 4(\mathrm{mg} / \mathrm{dL})$ & 0.02 & 0.80 & -0.23 & 0.02 & -0.01 & 0.86 \\
\hline Proteinuria (uPCI) & 0.39 & 0.001 & 0.48 & $<0.001$ & 0.41 & $<0.001$ \\
\hline Leukocyturia & 0.26 & 0.008 & 0.21 & 0.03 & 0.19 & 0.06 \\
\hline Haematuria & 0.13 & 0.18 & 0.09 & 0.38 & 0.11 & 0.24 \\
\hline SLEDAI-2K global score & 0.27 & 0.006 & 0.42 & $<0.001$ & 0.29 & 0.004 \\
\hline SLEDAI-2K renal score & 0.39 & 0.001 & 0.43 & $<0.001$ & 0.35 & 0.001 \\
\hline $\begin{array}{l}\text { SLEDAI-2K-extrarenal } \\
\text { score }\end{array}$ & -0.08 & 0.42 & -0.18 & 0.74 & -0.11 & 0.27 \\
\hline
\end{tabular}

at 4 months. The AUC for uMCP-1 was 0.77 (95\% CI: 0.65$0.89 ; p<0.001)$. At the maximum Youden index of 0.44 , the cutoff value for uMCP-1 was $3,175 \mathrm{pg} / \mathrm{mg}$ creatinine. This gave a sensitivity of 0.86 , specificity of $0.58, \mathrm{PPV}$ of 0.37 , and NPV of 0.94 for the prediction of LN activity.

\section{Discussion}

We have previously reported in a cross-sectional study that uMCP-1 levels were significantly elevated in patients with active LN compared to those with inactive renal disease [11]. On follow-up of our cohort, uMCP-1 levels were consistently higher in patients with active LN compared to those with inactive LN. The highest uMCP-1 levels were observed in those with renal relapses $(n=13)$ which their uMCP-1 levels decreased progressively with treatment. These findings are consistent with those reported to date from the few other longitudinal studies in the literature $[8,20,21]$. The Ohio SLE study followed 80 patients with SLE with and without LN and 28 healthy controls [8]. uMCP-1 levels were significantly higher in patients with renal flares $(n=25)$ than those with nonrenal flares $(n=22)$, SLE renal disease control subjects $(n=15)$, SLE nonrenal flare control subjects $(n=18)$, and healthy individuals $(n=28)$. uMCP-1 levels decreased over several months in patients who responded to treatment but were persistently high in nonresponders [8]. In another longitudinal study $(n=20)$, Singh et al. [20] reported that uMCP-1 could distinguish those patients with active LN from those with inactive renal disease or stable SLE. During followup, uMCP-1 levels decreased significantly in those patients who achieved remission (CR/PR) but did not change in nonresponders [20]. Torabinejad et al. [21] assessed the role of uMCP-1 and urinary transforming growth factor- $\beta 2$ (uTGF$\beta 2$ ) in a longitudinal study involving 70 SLE patients and 10 healthy controls. They divided the SLE patients into 4 groups: 25 with active LN, 10 with remission LN, 25 with clinically active SLE and without LN, and 10 with SLE in remission and without LN. They demonstrated that the levels of both uMCP1 and uTGF- $\beta 2$ were significantly different in these groups. The highest levels were observed in the active LN group while the lowest were found in the controls. Both biomarkers decreased in response to treatment [21].

In our study patients, uMCP-1 levels correlated directly with proteinuria and inversely with serum albumin at recruitment and on follow-up. These findings corroborate with those reported in cross-sectional studies by Tucci et al. [22], Chan et al. [23], and Alzawawy et al. [24] and in a longitudinal study by Watson et al. [25]. Whereas Noris et al. [26] did not find this association.

At baseline and at 2 months, we found no association between uMCP-1 levels and serum creatinine or eGFR. Contradictory results have been reported in both crosssectional studies $[22,23,27,28]$ and a longitudinal study by Rovin et al. [8]. However, at end study, uMCP-1 levels in our patients were found to be associated with serum creatinine and eGFR. Several reasons can account for this last observation: "mild" CKD progression, use of reninangiotensin system (RAS) blockers in those patients with $\mathrm{CR} / \mathrm{PR}$, and relapse of $\mathrm{LN}(n=13)$ which is often associated with an element of acute kidney injury (AKI).

We also found significant correlations between uMCP1 with global SLEDAI-2K and renal SLEDAI-2K scores at all time points. Many authors had previously reported these findings in both cross-sectional studies $[23,27,28]$ and in the longitudinal study by Rovin et al. [8].

At both follow-up visits, there were no associations between uMCP-1 levels and anti-dsDNA Ab titres. These findings concur with those reported by Watson et al. [25]. At 2 months, uMCP-1 levels were significantly associated with serum complements (C3, C4). The associations between uMCP-1 levels and serological markers remain controversial. El-Shehaby et al. [27] found uMCP-1 levels to be associated 
TABLE 5: Follow-up characteristics of the patient subgroup with LN active at baseline.

\begin{tabular}{|c|c|c|c|}
\hline Parameters & Baseline & 2 months & 4 months \\
\hline Active LN (A) & $\mathrm{A}, n=47$ & $\mathrm{~A}, n=29$ & $\mathrm{~A}, n=19$ \\
\hline Inactive LN (IA) & & IA, $n=18$ & IA, $n=28$ \\
\hline Systolic blood pressure & $128 \pm 13.16$ & $131.69 \pm 12.62$ & $130.23 \pm 12.51$ \\
\hline$(\mathrm{mmHg})$ & & $121.86 \pm 11.73$ & $123.33 \pm 11.87$ \\
\hline Intergroup $p$ value & & 0.01 & 0.01 \\
\hline Diastolic blood pressure & $77.80 \pm 10.31$ & $80.73 \pm 10.76$ & $81.15 \pm 7.86$ \\
\hline$(\mathrm{mmHg})$ & & $72.73 \pm 8.25$ & $73.14 \pm 9.01$ \\
\hline Intergroup $p$ value & & 0.03 & 0.77 \\
\hline Serum albumin & $37.78 \pm 5.54$ & $37.60 \pm 5.02$ & $36.92 \pm 2.53$ \\
\hline$(35-50 \mathrm{~g} / \mathrm{L})$ & & $40.93 \pm 2.54$ & $40.66 \pm 3.74$ \\
\hline Intergroup $p$ value & & 0.01 & 0.01 \\
\hline Serum creatinine & 69 (IQR 33-252) & 81.97 (IQR 40-244) & 86 (IQR 48-224) \\
\hline$(44-80 \mu \mathrm{mol} / \mathrm{L})$ & & 67 (IQR 44-139) & 62 (IQR 41-143) \\
\hline Intergroup $p$ value & & 0.43 & 0.01 \\
\hline eGFR & $93.61 \pm 46.01$ & $88.56 \pm 40.88$ & $71.15 \pm 29.20$ \\
\hline$\left(60 \mathrm{~mL} / \mathrm{min} / 1.73 \mathrm{~m}^{2}\right)$ & & $97.93 \pm 31.81$ & $99 \pm 38.15$ \\
\hline Intergroup $p$ value & & 0.28 & 0.01 \\
\hline ESR & 38.5 (IQR 21-91) & 45 (IQR 22-92) & 32 (IQR 8-105) \\
\hline$(\mathrm{mm} / \mathrm{hr})$ & & 55 (IQR 10-103) & 36.50 (IQR 1-70) \\
\hline Intergroup $p$ value & & 0.48 & 0.78 \\
\hline Anti-dsDNA Ab titers & 35.18 (IQR 1.73-195.97) & 38.59 (IQR 0.74-267.61) & 13.75 (IQR 2.11-175.22) \\
\hline$(<30 \mathrm{IU})$ & & 13.82 (IQR 1.54-135.29) & 41.53 (IQR 2.07-252.85) \\
\hline Intergroup $p$ value & & 0.94 & 0.82 \\
\hline Serum C3 & $100.5 \pm 36.39$ & $96.44 \pm 32.54$ & $106.06 \pm 39.29$ \\
\hline (79-152 mg/dL) & & $113 \pm 43.05$ & $98.25 \pm 21.99$ \\
\hline Intergroup $p$ value & & 0.43 & 0.50 \\
\hline Serum C4 & $21.46 \pm 12.82$ & $20.08 \pm 10.12$ & $22.15 \pm 19.90$ \\
\hline$(16-38 \mathrm{mg} / \mathrm{dL})$ & & $28.52 \pm 16$ & $22.93 \pm 11.77$ \\
\hline Intergroup $p$ value & & 0.20 & 0.31 \\
\hline Proteinuria (uPCI) & 110 (IQR 10-510) & 120 (IQR 10-480) & 110 (IQR 10-510) \\
\hline (<20 mg/mmol creatinine) & & 30 (IQR 10-50) & 40 (IQR 10-50) \\
\hline Intergroup $p$ value & & $<0.001$ & $<0.001$ \\
\hline \multirow[t]{2}{*}{ Urinary leucocytes/HPF $\times 10^{6} / \mathrm{L}$} & 0 (IQR 0-20) & 0 (IQR 0-20) & 0 (IQR 0-20) \\
\hline & & 0 (IQR 0-10) & 0 (IQR 0-5) \\
\hline Intergroup $p$ value & & 0.31 & 0.009 \\
\hline \multirow[t]{2}{*}{ Urinary $\mathrm{RBC} / \mathrm{HPF} \times 10^{6} / \mathrm{L}$} & 0 (IQR 0-10) & 0 (IQR 0-20) & 0 (IQR 0-50) \\
\hline & & 0 (IQR 0-5) & 0 (IQR 0-20) \\
\hline Intergroup $p$ value & & 0.29 & 0.23 \\
\hline uMCP-1 & 9,317 (IQR 548-40,170) & 5,031 (IQR 1,953.79-18,408) & 7,092.95 (IQR 1,208.69-17,070) \\
\hline (pg/mg creatinine) & & 2,955 (IQR 0-12,920) & 2,202.16 (IQR 0-10,573) \\
\hline Intergroup $p$ value & & $<0.001$ & 0.001 \\
\hline SLEDAI-2K & 8 (IQR 0-18) & 6 (IQR 0-18) & $8($ IQR 4-16) \\
\hline (global: 0-105) & & 0 (IQR 0-12) & 2 (IQR 0-12) \\
\hline Intergroup $p$ value & & $<0.001$ & $<0.001$ \\
\hline
\end{tabular}


TABLE 5: Continued.

\begin{tabular}{lccc}
\hline Parameters & Baseline & 2 months & 4 months \\
Active LN (A) & $\mathrm{A}, n=47$ & $\mathrm{~A}, n=29$ & $\mathrm{~A}, n=19$ \\
Inactive LN (IA) & & $\mathrm{IA}, n=18$ & $\mathrm{IA}, n=28$ \\
\hline SLEDAI-2K & 4 (IQR 0-16) & 4 (IQR 0-12) & 4 (IQR 4-16) \\
(renal: 0-16) & & 0 (IQR 0-8) & 0 (IQR 0-12) \\
Intergroup $\boldsymbol{p}$ value & & $<\mathbf{0 . 0 0 1}$ & $<\mathbf{0 . 0 0 1}$ \\
\hline SLEDAI-2K & 4 (IQR 0-12) & 2 (IQR 0-10) & 4 (IQR 0-8) \\
(extrarenal: 0-89) & 0 (IQR 0-8) & 2 (IQR 0-4) \\
Intergroup $\boldsymbol{p}$ value & 0.10 & 0.65 \\
\hline
\end{tabular}

TABLE 6: Area under the curve (AUC) of ROC curves for uMCP-1 and standard biomarkers for LN activity on longitudinal follow-up.

\begin{tabular}{|c|c|c|c|c|c|c|c|c|c|c|c|c|}
\hline \multirow{2}{*}{ Variables } & \multicolumn{4}{|c|}{ Baseline (95\% CI) } & \multicolumn{4}{|c|}{2 months (95\% CI) } & \multicolumn{4}{|c|}{4 months $(95 \% \mathrm{CI})$} \\
\hline & AUC & $p$ & LB & UB & AUC & $p$ & LB & UB & AUC & $p$ & $\mathrm{LB}$ & UB \\
\hline uMCP-1 & 0.82 & 0.001 & 0.73 & 0.91 & 0.82 & $<0.001$ & 0.73 & 0.90 & 0.87 & $<0.001$ & 0.78 & 0.95 \\
\hline $\begin{array}{l}\text { Serum } \\
\text { albumin }\end{array}$ & 0.25 & 0.001 & 0.13 & 0.35 & 0.23 & $<0.001$ & 0.13 & 0.33 & 0.21 & $<0.001$ & 0.10 & 0.31 \\
\hline $\begin{array}{l}\text { Serum } \\
\text { creatinine }\end{array}$ & 0.58 & 0.21 & 0.44 & 0.71 & 0.55 & 0.42 & 0.41 & 0.69 & 0.68 & 0.009 & 0.54 & 0.82 \\
\hline eGFR & 0.41 & 0.21 & 0.28 & 0.55 & 0.42 & 0.22 & 0.28 & 0.55 & 0.31 & 0.01 & 0.17 & 0.45 \\
\hline $\begin{array}{l}\text { Anti-dsDNA } \\
\text { Ab titres }\end{array}$ & 0.50 & 0.96 & 0.37 & 0.63 & 0.49 & 0.78 & 0.35 & 0.62 & 0.56 & 0.46 & 0.38 & 0.73 \\
\hline Serum C3 & 0.37 & 0.50 & 0.25 & 0.50 & 0.45 & 0.84 & 0.33 & 0.57 & 0.40 & 0.21 & 0.25 & 0.54 \\
\hline Serum C4 & 0.43 & 0.26 & 0.30 & 0.56 & 0.42 & 0.22 & 0.29 & 0.54 & 0.45 & 0.53 & 0.29 & 0.61 \\
\hline Proteinuria (uPCI) & 0.94 & $<0.001$ & 0.89 & 0.98 & 0.92 & $<0.001$ & 0.86 & 0.99 & 0.89 & $<0.001$ & 0.80 & 0.98 \\
\hline Haematuria & 0.72 & 0.001 & 0.60 & 0.84 & 0.54 & 0.49 & 0.41 & 0.67 & 0.62 & 0.07 & 0.48 & 0.77 \\
\hline Leukocyturia & 0.65 & 0.23 & 0.52 & 0.77 & 0.54 & 0.51 & 0.41 & 0.67 & 0.62 & 0.08 & 0.47 & 0.77 \\
\hline $\begin{array}{l}\text { SLEDAI-2K (renal } \\
\text { score) }\end{array}$ & 0.96 & $<0.001$ & 0.71 & 0.90 & 0.84 & $<0.001$ & 0.76 & 0.93 & 0.85 & $<0.001$ & 0.77 & 0.94 \\
\hline
\end{tabular}

with serum complements $\mathrm{C} 3$ and $\mathrm{C} 4$ but not with antidsDNA Ab titres. Alzawawy et al. [24] (cross-sectional study, 30 SLE patients) and Kiani et al. [10] (longitudinal study, 87 SLE patients) reported that uMCP-1 levels and anti-dsDNA positivity were highly associated, whereas Watson et al. [25] (longitudinal study, 64 paediatric SLE patients) reported an association between uMCP-1 and serum C3.

At all time points, the ROC curves for uMCP-1 showed it to be a good consistent noninvasive marker for detection of LN activity. AUCs at all three visits were very good and ranged from 0.82 to 0.87 with sensitivities of $0.87-0.90$ and specificities of 0.61-0.79. Torabinejad et al. [21] in their mixed SLE/LN cohort reported that UMCP-1 had an AUC of 0.90 with a sensitivity of 0.94 and specificity of 0.80 for diagnosis of LN regardless of SLE activity at baseline. In our study, uMCP-1 consistently outperformed the usual blood and urinary markers as well as the serological markers, that is, anti-dsDNA Ab titres and serum complements. However, uMCP-1 was not superior to proteinuria and SLEDAI-2K renal score for detection of LN activity. This may be due to the fact that both proteinuria and SLEDAI-2K renal score were included as major criteria in the definition of LN activity.
We also examined the ROC curve for uMCP-1 of the preceding visit which showed that a cutoff value of $3,175 \mathrm{pg} / \mathrm{mg}$ creatinine had a good sensitivity but lowish specificity for discriminating between active and inactive LN. Given the rather poor positive predictive value of 0.37 , a uMCP-1 cutoff level of $3,175 \mathrm{pg} / \mathrm{mg}$ creatinine did not have the potential to predict LN activity. However, uMCP-1 levels of less than 3,175 pg/mg creatinine had the potential to predict the absence of LN activity with a negative predictive value of $94 \%$.

In patients with LN active at baseline $(n=47)$, uMCP-1 levels fell significantly in response to treatment in all patients initially. In those who achieved CR/PR at end study $(n=$ 28), uMCP-1 levels continued to decrease further, whereas, in those with persistent NR $(n=19)$, the uMCP-1 which fell initially rose again at end of study.

In the 13 patients with LN relapse, uMCP-1 levels not only increased concurrently with the relapse but also achieved the highest levels and then decreased progressively with treatment. In the one patient with $\mathrm{NR}$ at baseline who relapsed at 2 months with increasing proteinuria and rising serum creatinine levels despite increased treatment, her uMCP-1 levels rose in tandem. Interestingly, one patient who 
TABLE 7: Predictors of LN outcome at 4 months' follow-up.

\begin{tabular}{|c|c|c|c|c|c|c|}
\hline \multirow{2}{*}{ Variables } & \multirow{2}{*}{$\beta$} & \multirow{2}{*}{ S.E } & \multirow{2}{*}{$p$} & \multirow{2}{*}{ OR } & \multicolumn{2}{|c|}{$95 \%$ CI for $\operatorname{Exp}(\beta)$} \\
\hline & & & & & Lower & Upper \\
\hline uMCP-1 & 0 & 0 & 0.15 & 1.000 & 1.000 & 1.000 \\
\hline Serum albumin & -0.18 & 0.08 & 0.02 & 0.83 & 0.71 & 0.97 \\
\hline Serum creatinine & 0.001 & 0.01 & 0.97 & 1.001 & 0.96 & 1.03 \\
\hline eGFR & -0.005 & 0.01 & 0.70 & 0.99 & 0.96 & 1.02 \\
\hline Proteinuria (uPCI) & 11.98 & 5.63 & 0.03 & 4.93 & 2.59 & 9.95 \\
\hline SLEDAI-2K (renal score) & 0.09 & 0.11 & 0.45 & 1.09 & 0.86 & 1.37 \\
\hline
\end{tabular}

$R^{2} 0.39$ (Hosmer and Lemeshow's), 0.32 (Cox and Snell), and 0.49 (Nagelkerke). Model $x^{2}=38.14, p<0.001 . \beta$ : beta; SE: standard error; OR; odds ratio = $\operatorname{Exp}(\beta)$; CI: confidence interval.

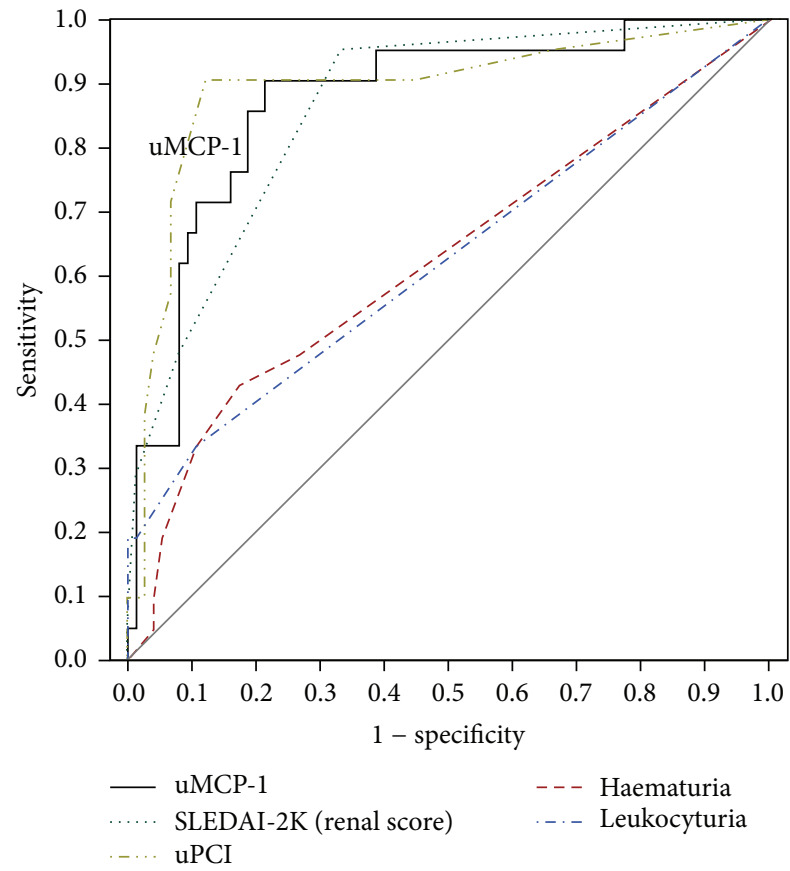

FIGURE 2: Receiver operating characteristic curve (ROC) of uMCP-1 compared with those of urinary parameters and SLEDAI-2K (renal) for the diagnosis of LN activity at 4 months. The black solid curve represents the uMCP-1; the area under the curve (AUC) was 0.87 $(p<0.001)$. The AUC for proteinuria was $0.89(p<0.001)$ and those for haematuria and leukocyturia were $0.62(p=0.07)$ and $0.62(p=0.08)$, respectively. The AUC for SLEDAI-2K was 0.85 ( $p<$ $0.001)$. Thus, uMCP-1 was better than haematuria and leukocyturia and essentially similar to proteinuria (uPCI) and SLEDAI-2K renal score for detection of LN activity at 4 months.

was initially in remission but relapsed at end study showed undetectable uMCP-1 levels throughout. This can perhaps be explained by MCP-1 gene polymorphism with her lacking the MCP-1 gene just like the MCP-1 knockout mice of the MRL/lpr lupus model [29] or her MCP-1 gene could have undergone mutation. Kim et al. [30] and Tucci et al. [22] had earlier reported MCP-1 gene polymorphism in SLE patients with LN except these authors had reported on the dominant allele and its predisposition to LN. Kim et al. [30] reported that a genetic polymorphism in the $5^{\prime}$ flanking region of the
MCP-1 gene is associated with LN in SLE patients. Tucci et al. [22] reported that SLE patients with an A/G or G/G MCP-12518 genotype have a higher risk of developing LN.

Multiple logistic regression analysis showed that only proteinuria and serum albumin were independent predictors of LN activity or relapse but not uMCP-1. This may again be due to the fact that both proteinuria and serum albumin were included in the definition of LN activity. We hypothesize that had the definition also incorporated the histological class as well as the activity index (AI) and chronicity index (CI) of recent renal biopsies and these parameters entered into the regression model, uMCP-1 could well have emerged as an independent predictor. In this context, Chan et al. [23] found that uMCP-1 mRNA was significantly higher in patients with active $\mathrm{LN}$ than in those with inactive $\mathrm{LN}$, or those with inactive nonrenal SLE and healthy controls. uMCP-1 mRNA correlated significantly with SLE disease activity indices and with the histological AI. However, uMCP-1 as measured by ELISA did not correlate with the histological AI.

Alternatively, the diagnostic performance of uMCP-1 could be improved when measured by the conventional assay method (ELISA) in combination with other urine proteins as demonstrated by Susianti et al. [31] or by using Multiplex bead assays (Luminex) which are able to detect a large panel of different cytokines in a single blood or urine sample [32]. In the literature, there are some data available on the use of multiplex bead assays for blood cytokine levels but very little data for urine cytokine levels [33]. Further studies are needed to validate this approach for the measurement of both blood and, particularly, urine cytokines [33]. Susianti et al. [31] assessed the role of urinary TGF- $\beta 1$, MCP-1, NGAL, and IL-17 in adults with $\mathrm{LN}(n=70)$. The patients were divided into 3 groups: 38 with severe LN (class III-IV LN patients), 12 with mild LN (class I-II LN patients), and 20 healthy controls. All biomarkers were measured by ELISA using a human kit for each biomarker. The authors found that all four biomarkers had good diagnostic performances. uNGAL had the best sensitivity and specificity followed by uMCP-1, uIL17 , and $\mathrm{uTGF}-\beta 1$. The best sensitivities and specificities were shown by the combination of UTGF- $\beta 1$ and uNGAL followed by uMCP-1 and UNGAL.

As part of the overall thesis project, we have also compared UNGAL and UMCP1 in this patient cohort and found that both biomarkers showed good performances for 
detection of LN activity (data not shown and not previously published) [34]. However, the AUC values as well as sensitivities and specificities for UMCP-1 were greater than those for uNGAL. Thus, uMCP-1 appears superior to uNGAL as a noninvasive diagnostic marker for active LN. Nonetheless, these markers in combination may be superior to either use in isolation.

The performance of uMCP-1 can also conceivably be improved by using one of the system biology approaches "omics." In general, these approaches are used for the universal detection of genes (genomics), mRNA (transcriptomics), proteins (proteomics), and metabolites (metabolomics) in a specific biological sample in a nontargeted and nonbiased manner [35]. He et al. [36] recently described the application of omics-based methodology for the study of kidney diseases. They discussed omics data integration in terms of improving early detection, predicting disease progression, and monitoring treatment response. Additionally, the omics tools may also improve our understanding of LN renal regulatory events and help identify new biomarkers and therapeutic targets [37].

In this modern era with the establishment of specialized SLE/LN centres, relapses and/or reactivation and/or NR have reduced in frequency and severity. Nonetheless, these remain a major issue in the management of LN patients. One reason for this is that the natural course of LN is typified by relapseremission and to perform repeated renal biopsies for each LN relapse not only is highly traumatic but may lead to complications and is probably unethical beyond a certain maximal number in a given time frame. Thus, serial uMCP-1 monitoring in conjunction with the usual clinical parameters can obviate repeated "invasive" renal biopsies.

The other main reason for $\mathrm{LN}$ and/or reactivation and/or $\mathrm{NR}$ is that patient noncompliance which has only been recently recognized. Many studies have shown that significant nonadherence to medications occurs not only in renal transplant patients [38-40] but also in lupus patients leading to adverse outcomes [41-43]. In our cohort, several patients were nonadherent to the prescribed dose of corticosteroids or immunosuppressive drugs. In addition, they were also taking herbal and/or traditional medications. These included $3 / 13$ of the relapsers and several with NR at recruitment. Despite repeated counseling on the importance of adherence to prescribed medications, one patient with NR at recruitment remained recalcitrant and suffered a relapse at end of study.

The main limitation of this study was the time lag between urine collections for uMCP-1 with initial renal biopsy. Thus, it was not possible to correlate uMCP-1 with the histological classes of LN. Another limitation was the (still) relatively small number of patients recruited and the short followup of only 4 months due to cost (predominantly) and time constraints.

In conclusion, uMCP-1 levels were markedly increased in those patients with active LN in particular those with renal relapse and correlated significantly with $\mathrm{LN}$ activity. uMCP-1 was able to distinguish active LN and/or relapse from inactive renal disease. It had consistently good diagnostic performances with a good sensitivity and moderate specificity for detection of $\mathrm{LN}$ activity and/or relapse. It also had a good sensitivity albeit lowish specificity for prediction of LN activity and/or relapse. Perhaps the usefulness of this biomarker could be improved by incorporating several other new markers currently also under study into a panel for assessing LN activity, somewhat similar to that recently validated by the FDA (USA) for acute kidney injury (AKI, NephroCheck). NephroCheck identifies the presence of 2 proteins (insulin-like growth-factor binding protein 7 (IGFBP7) and tissue inhibitor of metalloproteinases (TIMP-

2)) in the urine of AKI patients.

Although uMCP-1 was not an independent predictor for LN activity, it could serve as an adjunctive marker if the clinical diagnosis of LN activity remains uncertain. Additionally, it may identify early relapse of $\mathrm{LN}$, thus facilitating improved grading of LN activity in this complex disease leading to earlier treatment and better outcome. A larger, prospective, longitudinal study for a longer follow-up for at least of 2-3 years recruiting patients at the time of their renal biopsies is indicated.

\section{Disclosure}

The paper has been seen and approved by all authors and it is not under consideration for publication elsewhere in a similar form.

\section{Conflict of Interests}

The authors declare that there is no conflict of interests regarding the publication of this paper.

\section{Acknowledgments}

The authors thank UKMMC and MAA Kidney Medicare Charity Fund for funding their project. They thank the Dean and Medical Director, UKMMC, for his kind permission to publish these data and extend their gratitude to Rahimah Ismail and Rafidah Mamat for their help in the preparation of urine samples for the biomarker assay. This study was supported by a grant from the Faculty of Medicine, UKM (FF-446-2011), and another from the MAA Medicare Kidney Charity Fund.

\section{References}

[1] S. M. Korbet, E. J. Lewis, M. M. Schwartz et al., "Factors predictive of outcome in severe lupus nephritis," The American Journal of Kidney Diseases, vol. 35, no. 5, pp. 904-914, 2000.

[2] J. Reyes-Thomas, I. Blanco, and C. Putterman, "Urinary biomarkers in lupus nephritis," Clinical Reviews in Allergy \& Immunology, vol. 40, no. 3, pp. 138-150, 2011.

[3] A. Chaib, N. Mellilo, S. R. Sangle et al., "Antiphospholipid antibodies and increased bleeding complications following renal biopsy: a single centre study," Arthritis \& Rheumatism, vol. 56, abstract supplement, 2007.

[4] J. E. Balow, "Clinical presentation and monitoring of lupus nephritis," Lupus, vol. 14, no. 1, pp. 25-30, 2005. 
[5] A. Matrat, C. Veysseyre-Balter, P. Trolliet et al., "Simultaneous detection of anti-Clq and anti-double stranded DNA autoantibodies in lupus nephritis: predictive value for renal flares," Lupus, vol. 20, no. 1, pp. 28-34, 2011.

[6] E. Tarabra, S. Giunti, F. Barutta et al., "Effect of the monocyte chemoattractant protein-1/CC chemokine receptor 2 system on nephrin expression in streptozotocin-treated mice and human cultured podocytes," Diabetes, vol. 58, no. 9, pp. 2109-2118, 2009.

[7] S. D. Marks, S. J. Williams, K. Tullus, and N. J. Sebire, "Glomerular expression of monocyte chemoattractant protein-1 is predictive of poor renal prognosis in paediatric lupus nephritis," Nephrology Dialysis Transplantation, vol. 23, no. 11, pp. 35213526, 2008.

[8] B. H. Rovin, H. Song, D. J. Birmingham, L. A. Hebert, C. Y. $\mathrm{Yu}$, and H. N. Nagaraja, "Urine chemokines as biomarkers of human systemic lupus erythematosus activity," Journal of the American Society of Nephrology, vol. 16, no. 2, pp. 467-473, 2005.

[9] S. Tian, J. Li, L. Wang et al., "Urinary levels of RANTES and $\mathrm{M}$-CSF are predictors of lupus nephritis flare," Inflammation Research, vol. 56, no. 7, pp. 304-310, 2007.

[10] A. N. Kiani, K. Johnson, C. Chen et al., "Urine osteoprotegerin and monocyte chemoattractant protein-1 in lupus nephritis," Journal of Rheumatology, vol. 36, no. 10, pp. 2224-2230, 2009.

[11] S. Alharazy, N. C. T. Kong, M. Mohd, S. A. Shah, A. Báin, and A. H. Abdul Gafor, "Urinary monocyte chemoattractant protein and lupus nephritis activity," Journal of Clinical \& Cellular Immunology, vol. 5, article 187, 2014.

[12] S. M. Alharazy, N. C. T. Kong, M. Mohd, S. A. Shah, A. H. Abdul-Gafor, and A. Báin, "The role of urinary neutrophil gelatinase-associated lipocalin in lupus nephritis," Clinica Chimica Acta, vol. 425, pp. 163-168, 2013.

[13] M. C. Hochberg, "Updating the American College of Rheumatology revised criteria for the classification of systemic lupus erythematosus," Arthritis \& Rheumatism, vol. 40, no. 9, p. 1725, 1997.

[14] N. C. T. Kong, "Pulse Cyclophosphamide versus added dual filtration plasmapheresis (DFPP) therapy for severe lupus nephritis," UKM Research Clinical Trial Code FF-324-2011, 2010.

[15] D. D. Gladman, D. Ibañez, and M. B. Urowltz, "Systemic lupus erythematosus disease activity index 2000," Journal of Rheumatology, vol. 29, no. 2, pp. 288-291, 2002.

[16] K. Yamaji, Y.-J. Kim, H. Tsuda, and Y. Takasaki, "Long-term clinical outcomes of synchronized therapy with plasmapheresis and intravenous cyclophosphamide pulse therapy in the treatment of steroid-resistant lupus nephritis," Therapeutic Apheresis and Dialysis, vol. 12, no. 4, pp. 298-305, 2008.

[17] G. Ruiz-Irastorza, G. Espinosa, M. A. Frutos et al., "Diagnosis and treatment of Lupus nephritis: consensus document from the systemic auto-immune disease group (GEAS) of the Spanish society of internal medicine (SEMI) and the Spanish Society of Nephrology (S.E.N.)," Nefrologia, vol. 32, supplement 1, pp. 1-45, 2012.

[18] C. Bombardier, D. D. Gladman, M. B. Urowitz et al., "Derivation of the SLEDAI. A disease activity index for lupus patients. The Committee on Prognosis Studies in SLE," Arthritis \& Rheumatism, vol. 35, no. 6, pp. 630-640, 1992.

[19] W. J. Youden, "Index for rating diagnostic tests," Cancer, vol. 3, no. 1, pp. 32-35, 1950.

[20] R. G. Singh, S. S. Rathore, S. K. Behura, and N. K. Singh, "Urinary MCP-1 as diagnostic and prognostic marker in patients with lupus nephritis flare," Lupus, vol. 21, no. 11, pp. 1214-1218, 2012.
[21] S. Torabinejad, R. Mardani, Z. Habibagahi et al., "Urinary monocyte chemotactic protein-1 and transforming growth factor- $\beta$ in systemic lupus erythematosus," Indian Journal of Nephrology, vol. 22, no. 1, pp. 5-12, 2012.

[22] M. Tucci, E. V. Barnes, E. S. Sobel et al., "Strong association of a functional polymorphism in the monocyte chemoattractant protein 1 promoter gene with lupus nephritis," Arthritis \& Rheumatism, vol. 50, no. 6, pp. 1842-1849, 2004.

[23] R. W.-Y. Chan, F. M.-M. Lai, E. K.-M. Li et al., "Expression of chemokine and fibrosing factor messenger RNA in the urinary sediment of patients with lupus nephritis," Arthritis \& Rheumatism, vol. 50, no. 9, pp. 2882-2890, 2004.

[24] A. Alzawawy, M. Zohary, M. Ablordiny, and M. Eldalie, "Estimation of monocyte-chemoattractantprotein-1 (Mcp-1) level in patients with lupus nephritis," International Journal of Rheumatic Diseases, vol. 12, no. 4, pp. 311-318, 2009.

[25] L. Watson, K. Tullus, C. Pilkington et al., "Urine biomarkers for monitoring juvenile lupus nephritis: a prospective longitudinal study," Pediatric Nephrology, vol. 29, no. 3, pp. 397-405, 2014.

[26] M. Noris, S. Bernasconi, F. Casiraghi et al., "Monocyte chemoattractant protein-1 is excreted in excessive amounts in the urine of patients with lupus nephritis," Laboratory Investigation, vol. 73, no. 6, pp. 804-809, 1995.

[27] A. El-Shehaby, H. Darweesh, M. El-Khatib et al., "Correlations of urinary biomarkers, TNF-like weak inducer of apoptosis (TWEAK), osteoprotegerin (OPG), monocyte chemoattractant protein-1 (MCP-1), and IL-8 with lupus nephritis," Journal of Clinical Immunology, vol. 31, no. 5, pp. 848-856, 2011.

[28] R. F. Rosa, K. Takei, N. C. Araújo, S. M. A. Loduca, J. C. M. Szajubok, and W. H. Chahade, "Monocyte chemoattractant-1 as a urinary biomarker for the diagnosis of activity of lupus nephritis in Brazilian patients," Journal of Rheumatology, vol. 39, no. 10, pp. 1948-1954, 2012.

[29] G. H. Tesch, S. Maifert, A. Schwarting, B. J. Rollins, and V. R. Kelley, "Monocyte chemoattractant protein 1-dependent leukocytic infiltrates are responsible for autoimmune disease in MRL-Fas(lpr) mice," Journal of Experimental Medicine, vol. 190, no. 12, pp. 1813-1824, 1999.

[30] H. L. Kim, D.-S. Lee, S. H. Yang et al., "The polymorphism of monocyte chemoattractant protein-1 is associated with the renal disease of SLE," American Journal of Kidney Diseases, vol. 40, no. 6, pp. 1146-1152, 2002.

[31] H. Susianti, V. M. Iriane, S. Dharmanata et al., "Analysis of urinary TGF- $\beta 1$, MCP-1, NGAL, and IL-17 as biomarkers for lupus nephritis," Pathophysiology, vol. 22, no. 1, pp. 65-71, 2015.

[32] B. H. Rovin and X. Zhang, "Biomarkers for lupus nephritis: the quest continues," Clinical Journal of the American Society of Nephrology, vol. 4, no. 11, pp. 1858-1865, 2009.

[33] Z. Adhya, S. Borozdenkova, and M. Y. Karim, "The role of cytokines as biomarkers in systemic lupus erythematosus and lupus nephritis," Nephrology, Dialysis, Transplantation, vol. 26, no. 10, pp. 3273-3280, 2011.

[34] S. Alharazy, Urinary neutrophil gelatinase-associated lipocalin and monocyte chemoattractant protein-1 as biomarkers of renal disease activity in lupus nephritis [Ph.D. thesis], 2015, UKM Research Clinical Trial Code (FF-446-2011).

[35] R. P. Horgan and L. C. Kenny, "SAC review 'Omic' technologies: genomics, transcriptomics, proteomics and metabolomics," The Obstetrician \& Gynaecologist, vol. 13, pp. 189-195, 2011.

[36] J. C. He, P. Y. Chuang, A. Ma'Ayan, and R. Iyengar, "Systems biology of kidney diseases," Kidney International, vol. 81, no. 1, pp. 22-39, 2012. 
[37] C. C. Berthier, M. Kretzler, and A. Davidson, "From the large scale expression analysis of lupus nephritis to targeted molecular medicine," Journal of Data Mining in Genomics \& Proteomics, vol. 3, no. 3, 2012.

[38] K. E. C. Meyers, P. D. Thomson, and H. Weiland, "Noncompliance in children and adolescents after renal transplantation," Transplantation, vol. 62, no. 2, pp. 186-189, 1996.

[39] K. Denhaerynck, F. Dobbels, I. Cleemput et al., "Prevalence, consequences, and determinants of nonadherence in adult renal transplant patients: a literature review," Transplant International, vol. 18, no. 10, pp. 1121-1133, 2005.

[40] F. Dobbels, A. Hames, I. Aujoulat, N. Heaton, and M. Samyn, "Should we retransplant a patient who is non-adherent? A literature review and critical reflection," Pediatric Transplantation, vol. 16, no. 1, pp. 4-11, 2012.

[41] M. Adler, S. Chambers, C. Edwards, G. Neild, and D. Isenberg, "An assessment of renal failure in an SLE cohort with special reference to ethnicity, over a 25-year period," Rheumatology, vol. 45, no. 9, pp. 1144-1147, 2006.

[42] N. Costedoat-Chalumeau, Z. Amoura, J.-S. Hulot et al., "Very low blood hydroxychloroquine concentration as an objective marker of poor adherence to treatment of systemic lupus erythematosus," Annals of the Rheumatic Diseases, vol. 66, no. 6, pp. 821-824, 2007.

[43] F. Rivera and S. Anaya, "Lupus nephritis flare in young patients: relapse or nonadherence to treatment?" International Journal of Nephrology and Renovascular Disease, vol. 7, pp. 117-121, 2014. 


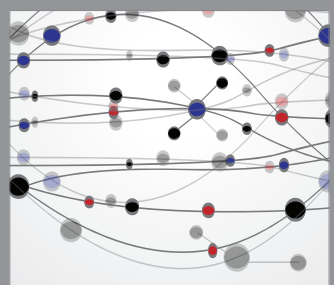

The Scientific World Journal
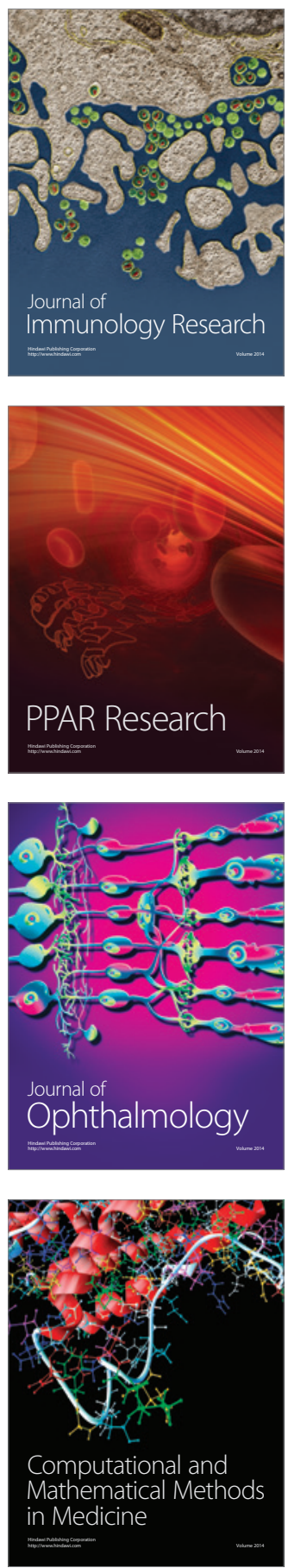

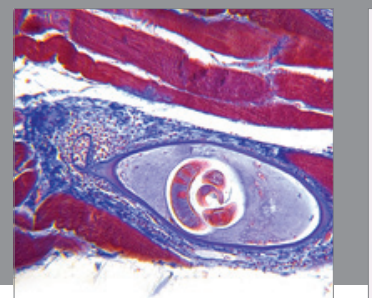

Gastroenterology

Research and Practice
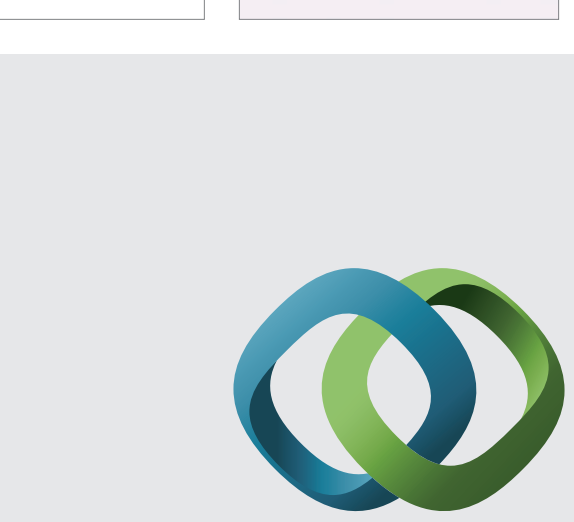

\section{Hindawi}

Submit your manuscripts at

http://www.hindawi.com
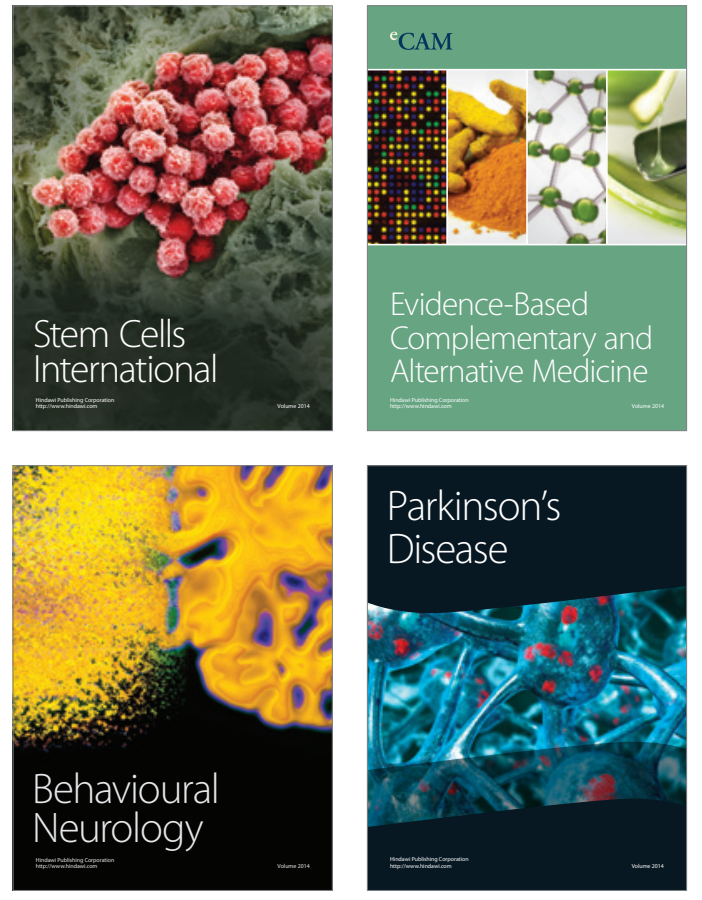
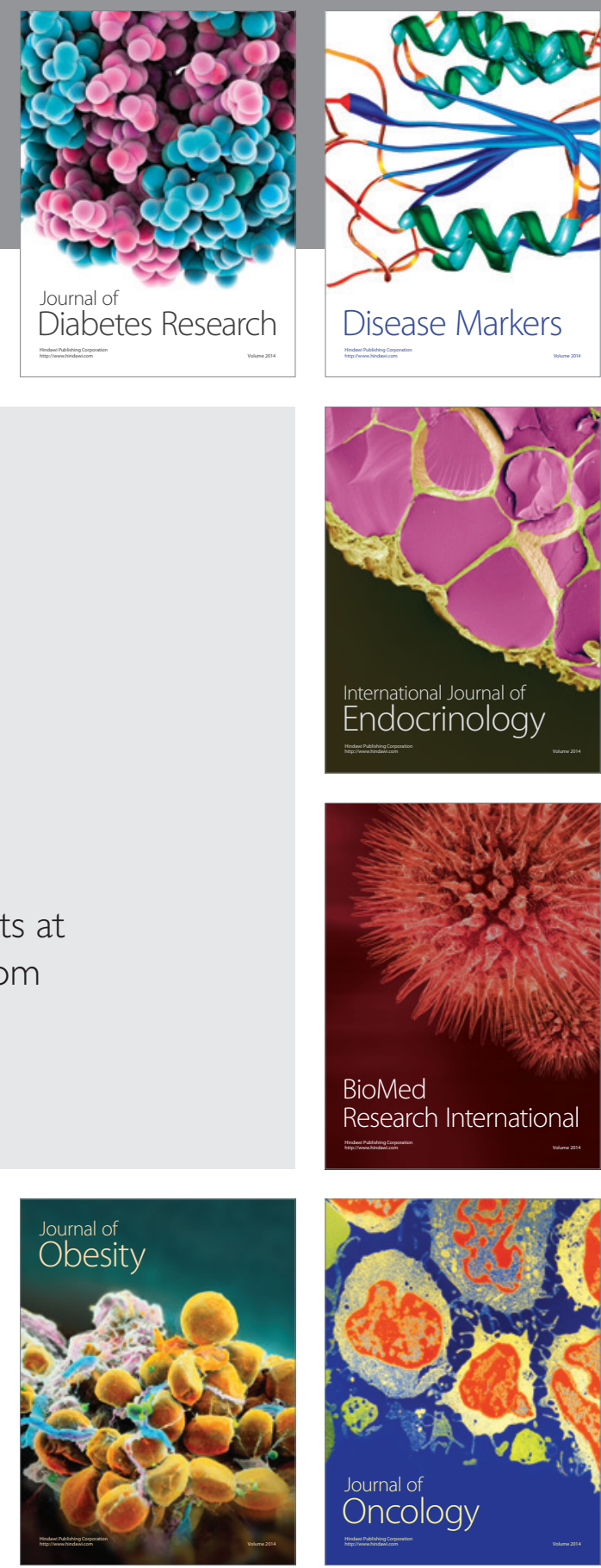

Disease Markers
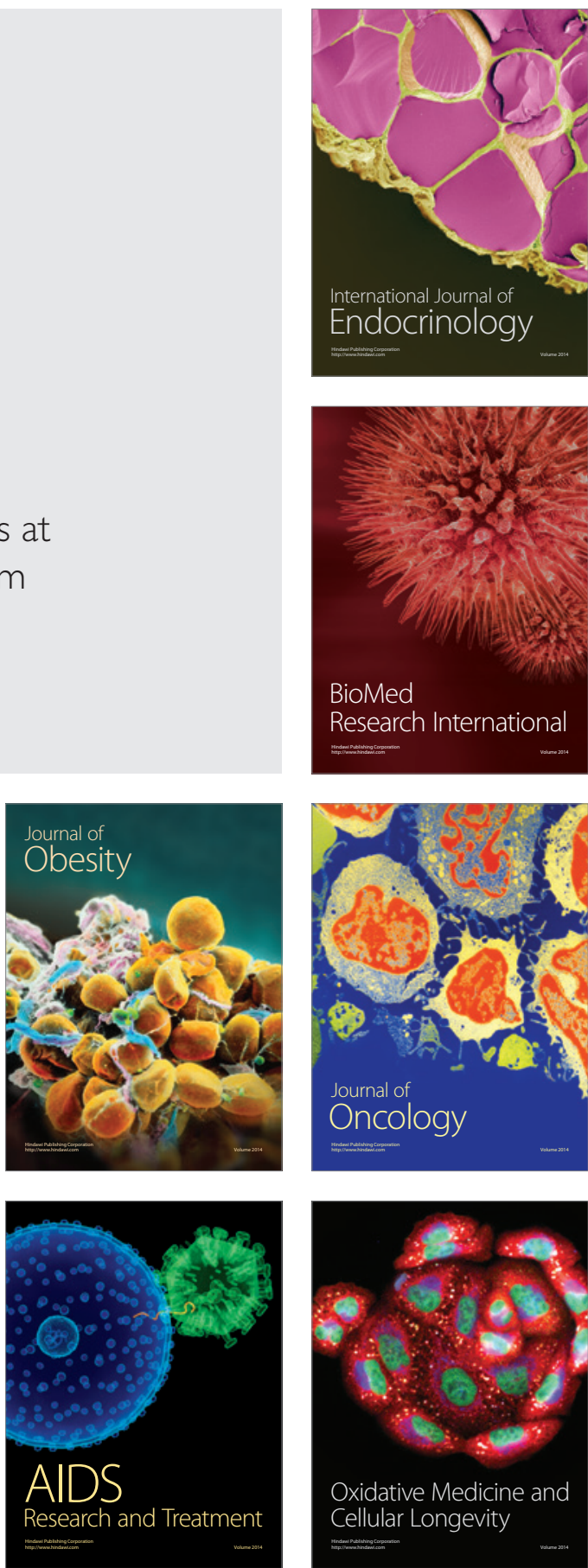